\title{
ANALYTIC HIERARCHY PROCESS: A MISSING LINK IN EXPLORING COMPLEXITY
} IN MENTAL MODELS.

\author{
Kemeth I Preiss \\ Faculty of Business \& Technology. University of Western Sydney (Macarthur), Campbellown, New \\ South Wales, Australia 2560.
}

\begin{abstract}
ARSTRACT: A systematic two-stage methodology integrating the criteria elicitation strengths of the Repertory Grid with the modelling power of the Analytic Hierarchy Process in prioritising the criteria for recruitment and placement decisions is described. Critical Success Factors for women direct-selling to women in a dynamic environment are presented as a case study. Revealed cognitive structures, conformities and constructing indices of a highly successful and a much less successful saleswoman are compared. Indices include frame differentiation, frame complexity, frame integration, construct centrality and construct ranking. The case study focuses on the complexity of the two mental maps and how the Aralytic Hierarchy Process addresses the limitations of using solely the Repertary Grid technique for analysing and representing the complexity of the decision criteria.
\end{abstract}

Keywords: Objectives, priority setting, marketing, values.

\section{Introduction}

Some problems are so complex that they need to be systematically displayed before they are understood [1]. Conversely, other problems can appear simple but have an underlying complexity. Systematically eliciting, representing and prioritising problem criteria allows for the exploration of the underlying complexity in the mental models that represent the problem criteria. A mental map is characterised by hierarchical structure and the more general property of linkage of connected clusters and nodes. Where nodes are supported by a 'tree' of other nodes that have implications for it $[2, p .317,3]$. Complexity frequently takes the form of hierarchy, and hierarchic systems have some common properties that are independent of the specific content [4].

The Analytical Hierarchic Process (AHP) [5] is a systematic method for constructing a hierarchy of altematives. However, the starting point in the construction of a decision hierarchy is the elicitation of the problem criteria for consideration Turban ['6] states that criteria should be selected prior to searching for decision alternatives. Nonqualifying altematives can then be eliminated. Dyer \& Forman [7] suggest that some problems may, however, lend themselves to specifying the criteria $\rightarrow$ alternatives apprasch whilst others allow the opposite, that is, altematives $\rightarrow$ criteris but add, that the process is iterative. They suggest that the criteria $\rightarrow$ altersatives approach is the most appropriate when delving into 'uncharted waters' and the opposite is appropriate after more experience and familiarity with the decision problem. Irrespective of which of the foregoing approaches is chosen, selecting the criteria in the problem structuring process requires more than arbitrary choices; a criteria selection method which Saaty \& Keams 18. p.105] describe is incremental in nature and, therefore, of questionable value. They state that a major problem with the incremental approach is that it 'more adequately reflects peoples' preferences, values, emotions and fears', and in addition, the relative importance of the criteria is not 'explicated'. Simply put, precisely defined criteria takes a back seat to intangible criteria.

In. essence, the incremental approach offers no formal method of capturing the range of possible perceptions. The relative power wielded by participants in the problem selection process using the incremental approach often acts as the prime influencer in the structuring of the problem. Saary \& Kearns [8] describe a number of systems 
approaches to eliciting decision criteria, they are: the Delphi Method [9], Strategic Assumption Surfacing and Testing [10] the Symmetrical Linkage System [11] and the Multiattribute Utility Theory [12]. They concede that all these methods are either cumbersome, time consuming, superficial or lack a suitable framework for strucnuring problems. The Repentory Gid (RepGrid) [13], in contrast, is a highly effective and information rich method for elicitating, structuring and representing decision criteria. It is a method that is based on a sound theory, and is extensively researched and widely used.

A two-stage model is explored here. where the RepGrid is used as the process for eliciting criteria and the Analytic Hierarchy Process. (AHP) for prioritising the criteria This method integrates a widely used managerial tool with a powerful mathematical modelling process.

The RepGrid has been applied to a diverse range of management issues. It has been demonstrated to be highly productive in exploring employee's concept of the meaning of work [14] and for analysing the nature of jobs $[15,16,17]$.

One method of evaluating the efficacy of any new approach is to compare it against current practices and then assess the valueadding performance of the proposed new approach. The criteria generated via the combined RepGrid/AHP is compared against a current practice for identifying Critical Success Factors $\left(\mathrm{CSF}^{\mathrm{s}}\right)$ of saleswomen direct-selling womens apparel to women in a dynamic sales environment. The data is extensively analysed to identify cognitive constructing indices, such as, frame differentiation, frame complexity, frame integration, construct centrality and construct ranking. Thesc indices were then used to highlight differences in the construct models of a successful and less successful saleswoman.

\section{Rep Grid Method}

Following years of consulting experience using mental modelling techniques for marketing and business strategy development and corporate change interventions, construct elicitation using the RepGrid has repeatedly been found to be a highly efficient process for generating. developing and representing decision criteria.
Senge [18] cites cases of corporate success where effective development of shared mental maps is given as a significant causal factor in achieving that success.

The RepGrid is a flexible tool for eliciting individual mental models using a consistent framework. It allows for the framing and comparing of cognitive constructs on an individual $\rightarrow$ individual, group $\rightarrow$ group or individual $\rightarrow$ group basis. Stewar \& Stewar [19] state that the RepGrid mental mapping technique - or just cognitive construct elicitation - usually identifies areas of importance on which to focus. This makes it an ideal tool for generating information to be fod into a modelling process.

Data produced. by the RepGrid in itself allows for extensive analysis of the information elicited, particularly in the exploration of cognitive complexity. Some RepGrid analysis techniques explore hierarchies within construct elicitation [3], however, concern has been expressed that the conventional RepGrid procedures do not necessarily tap into one-way relationships between constructs [20] Alternative analyses methods such as pyramiding [21], laddering, and implication grids $[3,22]$ provide some insight into hierarchical structures, however, such methods depend too much on high levels of verbal insight $[13,23]$.

\section{Traditional CSF Elicitation}

Traditional CSF elicitation and subsequent employee selection and placement decision-making incorporates prescribing standardised intelligence and personality profiles (created from standard pencil-and-paper tests) as representations of job requirements. The job applicant is then assessed and matched against those standardised profiles using that particular test protocol to determine whether the respondent's profile conforms 10 predetermined normative patterns.

Stevens [24], for example, studied 250 salesforces (in North America) and from assessment testing of more than 100,000 salespeople generated psychological characteristics which he fitted into four specific sales approaches [Table 1 lists a matching set of psychological characteristics and sales approaches]. 
Cosing selling. the salesperson usually starts with little but cold calls and aggressively initiates customer contact whilst employing all the technical skills of selling to clinch a deal which includes quickly establishing a prospect's emotional needs for the product.
* Extroverted

* Energetic

* Optimistic

* Strong work ethic

* Competitive

* Hopes for financial success but is unlikely to save or live frugally

* Positive antutude

* Highly self-confident.
Consultative selling: appropriate for a high technology products or "intelligent" services, like telecommunications or computer systems, consulting or legal services. Patience, interpersonal contact and aggressiveness are needed. Consultative selling requires a quick development of business relationships. and consultation with customers to determine their specific product needs.
* Career oriented, with hopes to advance into corporate management

* Status-and image-conscious

* Academic

* Patient

* Self-confident

* Independent and self-developmental

* Team oriented

* Not impulsive or willing to take extreme risks
Relationship selling. typified as being heavily dependent on long-term relationships between the salesperson and the customer and which requires great patience over long periods to cement a deal.
* Strong work ethic (feels guilty if doing nothing)

* Self-sufficient

* İdependent (doesn't like to be bossed)

* Cooperative

* Patient

* Traditional, tends to be conservative.

* Low career ambition

* Easily bored

*.Enjoys people

* High physical energy level

* Impulsive

* Tends to focus on home and other goals. and some telemarketing "order takers" who sell from a catalogue fall into this category.

\section{Table 1. Sales approaches with matched psychological characteristics.}

Contrary to considerable evidence [25, $26,27,28,29,30,31$, Stevens [24] and others [32] argue that improved sales performance flows from conformity to prescribed attributes, that is, closely matching people to a given set of psychological characteristics in the context of the four defined sales approaches listed above.

Such an argument is prescriptive in approach and often static in practice, and is aimed primarily at achieving predicability and certainty: a certainty that the person's mental structures fit as closely as possible the 'right type' profile, so that conformity is achieved and conflicts are minimised.
This static approach, ignores the highly dynamic nature of the business world and, in particular the sales world, where mental models and behaviours frequently change as a result of the complex interaction dynamics at the pointof-sale.

\section{An Ilustrative Case Study.}

A national women's apparel manufacturing and marketing organisation (better described as a small enterprise) conducted an investigation, using the Cattell $16 \mathrm{PF}$ [33] personality inventory, to identify 


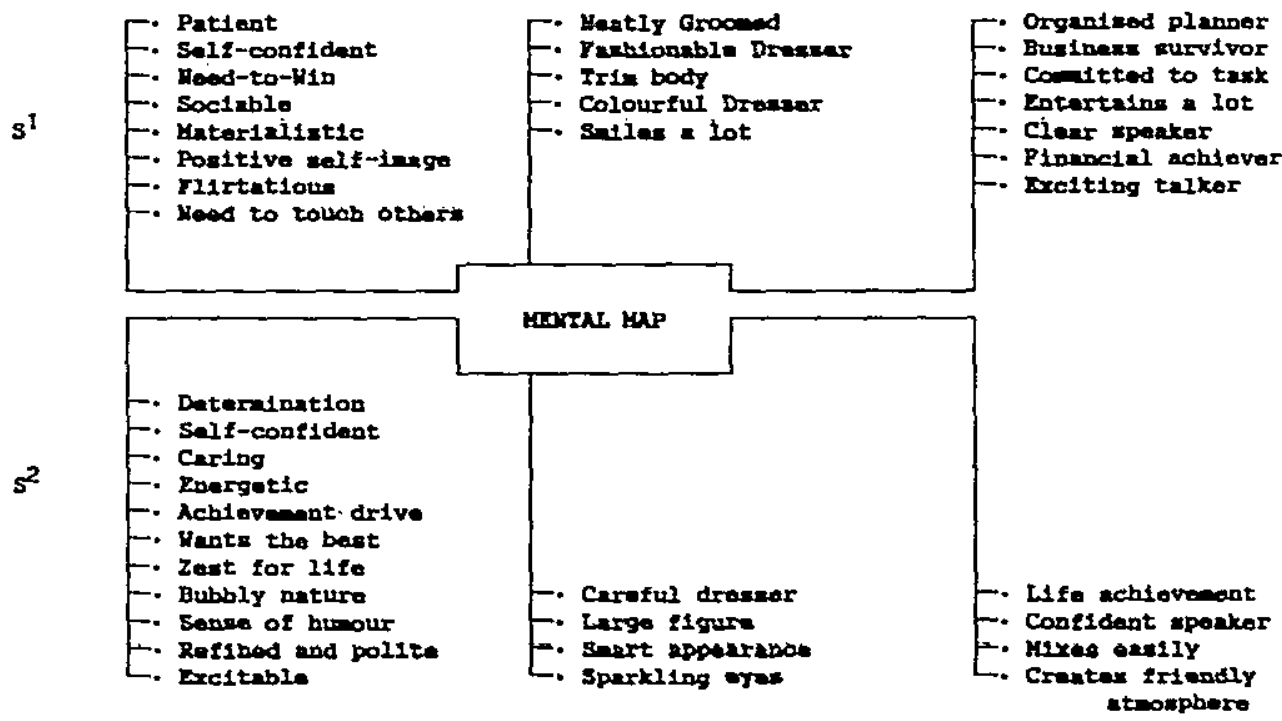

Table 2. Mental Map Construct Clusters for $S^{1}$ and $S^{2}$.

band gaps for $S^{2}$ on the Good vs Poor comparison $(t=-7.88,36 \mathrm{df}, \mathrm{p}<=2.41, \propto .05$, two-tail). but not for $S^{l}(\rho=-0.10,38 d f, p<=0.92, \propto .05$, two-tail).

\subsection{Frame Integration}

Frame integration refers to the degree of connectedness of the constructs, that is, how tightly 'packed' they are. A highly integrated reference frame is ore where there is a high correlation between all pairs of constructs. Thus, a maximally integrated reference frame is minimally complex, since each construct performs the sarne firiction as all other constructs. The measures of frame complexity and integration are an indication of the cognitive sophistication of the salesperson in defining $\operatorname{CSF}^{\mathrm{s}}$.

The construct intraclass correlations for $S^{1 / s}$ cognitive map was 0.37 (average root-mean-square) and 0.68 for $S^{2}$. The $S^{1}$ mental map of job constructs is less tightly packed than is $S^{2}$. This outcome is evidence that the mental map of $S^{2}$ is less complex and more highly integrated than $S^{1 / 5}$ (Figures 1 \& 2). The factor solution (Principal Component Analysis) for the $S^{1}$ map produced 3 factors which account for 26.7, 19.7 and 16.2 percent respectively (i.è., a total of 62.6 percent) of the variance in the grid. The three factors for the $S^{2}$ grid account for 52.6, 14.1 and 9.5 percent of the variance respectively (i.e., a total of 76.2 percent).

\subsection{Construct Centrality}

Construct centrality assesses the importance of a given construct in relation to the others and provides a measure to explain interconstruct variation. Intercomelation values are computed, summed across rows (by constructs) and then divided by the number of elements added to yield unweighted centrality values. Durn, et al. [17] propose that the respondent assess which of these constructs (CSF') ate the most important and then assign a weight to each. The constuct centrality score is then multiplied by these assigned weights. They argue that the resulting weighted score

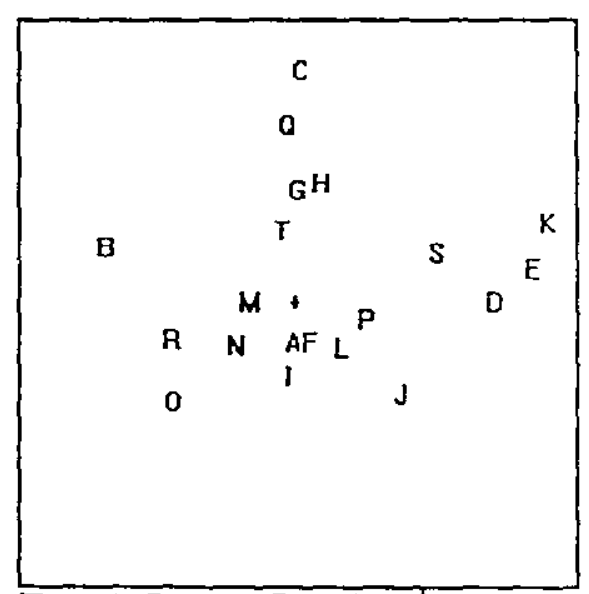

Figire 1. Constrice Custering S

presents a more accurate representation of the relative importance of each construct. The assessment of the weights, and then the priority or importance assigned to eacb construct, using this approach, relies on arbitrary decisions by each respondent that may have no consistent conceptual foundation or relativity in weightings. More 


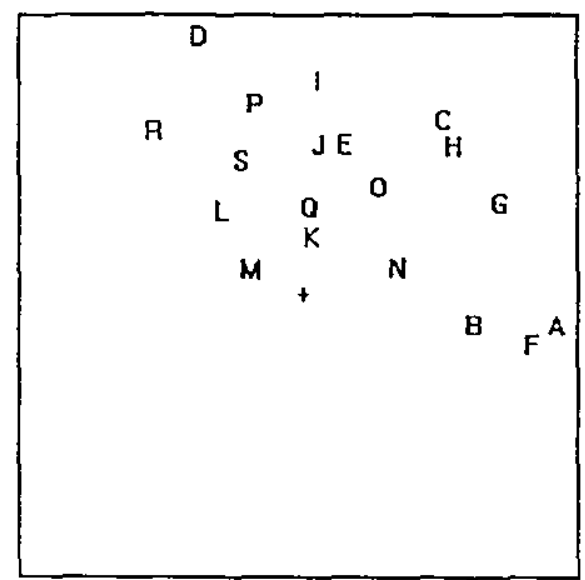

Figure 2. Construct Custering $S^{2}$

imporantly, it contradicts the basic thrust of mental modelling techniques, that is, to compare rather than assign values and mearing to a construct with respect to elements to which they relate. A more rigorous methodology is, therefore, required.

\section{Analytic Hierarchy Process (AHP)}

AfIP, extensively published by Saaty [5] and others $[8,35]$ is a process for assigning priorities to elements of a problem by comparing them in pairs with respect to their relative impact (weight or intensity) on a property they share in common, and then representing them in a hierarchy. Criteria are compared with each other, but onily once, thus yielding a half-matrix. The computer program, EXPERT CHOICE [36] based on the AHP methodology was used to graphically represent the $\mathrm{CSF}^{\text {in }}$ in a hierarchy starting with the overall goal. The nodes and leafs were analysed and represented as relationships between global and local priorities (Tables $3 \& 4$ ).

To simplify the nodal prioritisation process. constructs which were most similar in content were combined to reduce the comparisons to no more than seven constructs. This is the maximum recommended for each leaf in the nodes of the EXPERT CHOICE hierarchy. Constructs $D$ and $K$ in Figure 1 were combined in the $S^{1}$ bierarchy (now represented as $D$ ) as they were similar in nature and, were also ranked 12 and 13 respectively when comparing the initial ranking of the overall rating means.

Constructs $A$ and $F$ in Figure 2 (now represented as $A$ ), then $E$ and $H$ (now $E$, and finally $L J$ and $Q$ (now $D$ were also combined because of their similarity in content. Each construct was then compared against all others in a pair-wise manner to produce the overall priority of constructs. When prioritising using the AHP/EXPERT CHOICE method, an index of consistency (or inconsistency) is produced which is described as the Inconsistency Ratio (IR).
Sales Achievement

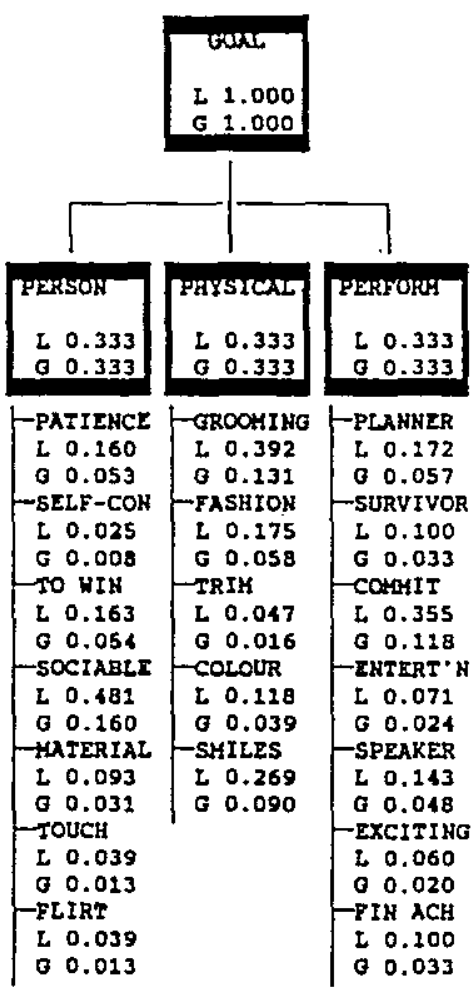

PERFORH --- Pertormance Characteristics PERSON --- Personality Tre1te

PHYSICAL -- Phyicical Trait:

R. COLOUR --- Colourful dreserer

H. ConatIT -.- Comemitment to tagk

I. ENTERT'A --O Enterte1na a lot

P. ExCITINO --- Exc1ting talker

H. FASHION --- Fashionable dreszer

A. FIH ACH -- Flnanclal achiovement

Q. FIIRT -- Pliztatious

H. GROOHING -.- Hantly Groosed

3. MATERTAL $\cdots$ Haterinliat1c

C. PATIEHCE -- Patience

B. PLAHNER --- Organtaed planner

D. SELF-CON -..- SeIf-con\&1dence/Solf-image

T. SMILES - - Sm1les a lot

o. SOCIXBLE - - Soctabio

L. SPEAKER -- Clear gpaker

z. SURVIVOR -.- BUxinese murv1vor

F. TO WIN --- Need to WIn

S. TOUCH - Ne Ned to touch others

O. TRIH --- Trim Body

L- LOCAL PRIORIJY: PRIORITY RELATIVE TO PARENT

G- GLOBAL PRIORITY: PRIORITY RELATIVE TO GOAL

Table 3. Nodal Hierarchy $\mathbf{S}^{1}$. 
Sales Achievement

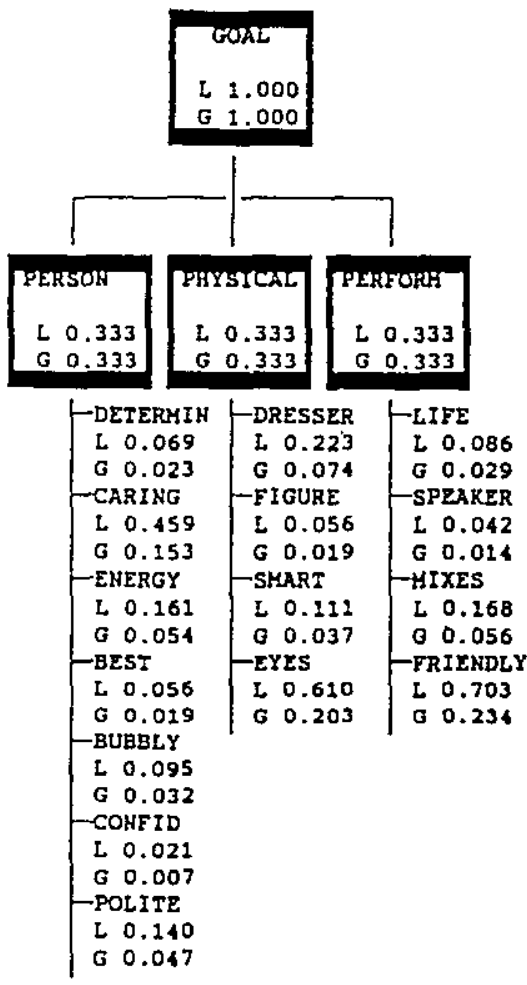

PERFORH --- Performance Characteriftica
PERSON --- Permonality traits PERSON -- Permonality traitz
PHYSICAL -- Phyajcal Charecteristics

G. BEST --- Wanta bext of things

I. BUBBLY =- Bubbly/Humorous/Exc1 table

D. CARIHO -- Care for People

B. CONFID - - Self-confidence

A. DETERMIN --- Achteve't Drtve/Daterain'n

L. DRESSSER --- Careful dresen

H. ENERGY -- Energy/Zent for Lifo

R. EYES -- Sparking eyea

H. FIGURE --- Large f1gure

S. FRIEHDLY --- Crostan friendly atmonphere

C. LIFE -- Etse achievament

o. MIXES -. MIXes easily

K. POLITE -. Rofined Pollte

P. SMART --- Smart appearance

N. SPEAKER -.- Confident apeaker

L - LOCAL PRIORITY: PRIORITY RELATIVE TO PARENT

G - GLOBAL PRIORITY: PRIORITY RELATIVE TO GOAL

\section{Table 4. Nodal Hicrarchy $S^{2}$}

Saaty \& Kearns [8] state that an IR greater than 0.10 should be investigated to determine from where in the pair-wise comparisons the inconsistency arises. $S^{2 *}$ priority ranking produced an inconsistency ratio of 0.11 whilst it was 0.06 for $S^{1}$.
Analysis of the nodal hierarchies was conducted at the Global Priority rather than the Local Priority level. This is not to discount the importance of the latter, but to maintain consistency in the form of information generated by the two different approaches to identifying CSF's.

Quite clearly, the level of hierarchy in $\mathrm{S}^{1 \text { 's }}$ Nodal Hierarchy model is greater than for $S^{2}$. The priority weightings for $S^{1}$ descended at a consistent incremental rate across all criteria, whereas, the priorities for $S^{2}$ were concentrated on the top three criteria, then rapidly fell away to a second group.

Global priority ratings were used to weight the top three CSF's for both subjects. The construct centrality (CC) factor was then multiplied by the Global Priority factor to produce a construct centrality weighting (CCW) as described by Dunn et al. [17]. The top three weighted $\mathrm{CSF}^{\text {s }}$ for $\mathrm{S}^{\mathrm{l}}$ are Sociable, Personal Grooming and Commitment to Task (i.e., $G M \& H$ ). The top three $\mathrm{CSF}^{\circ}$ for $\mathrm{S}^{2}$ are Creates Friendly Atmosphere, Sparkling Eyes and Care for People (i.e., $S, R$ \& $D$ ) (Table 5).

$\begin{array}{llll}\text { Construct } & \text { CC } & \text { W } & \text { CCW } \\ s^{1} & & \end{array}$

G. Likes people/

Sociable

M. Personal grooming $\quad .51 \quad .13 \quad .07$

H. Commitment to lask

$.41 \quad .11 \quad .05$

$s^{2}$

S. Creates friendly atmosphere

R. Sparkling eyes

D. Care for people

$\begin{array}{lll}.76 & .23 & .17 \\ .64 & .20 & .13 \\ .59 & .15 & .09\end{array}$

Table 5. Weighted Construct Centrality

10. Summary and conclusions

The real test of any new investigative methodology is how it compares with the results achieved through the use of the more generally accepted current methodology. The integrated RepGrid/AHP approach described 
here demonstrated considerable benefits over the traditional personal attribute pencil-andpaper methodology' for the identification of $\mathrm{CSF}^{\text {s }}$ for saleswoman. The combined RepGrid/AHP not only elicits a list of the

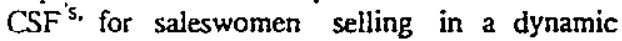
cnvironment, it also provides a measure of how saleswomen construct their cognitions about the CSFs. Basically, it addresses the two related issues of what the job incumbent thinks from her experience are the core factors necessary for success and how she thinks about them, that is, how they construct hierarchies within their mental models.

The cluster of cognitive constructs

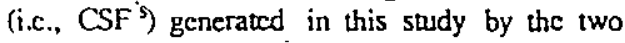
saleswomen very closely match the typical psychological characteristics identified by Stevens [24], for example, Patience, Selfconfidence, Enjoys Pcoplc and the Need-toWin. However, the CSF's clusters do not fit any one single sales approach identified by Stevens, they in fact cut across the four sales approaches. This outcome suggests at least two possible interpretations. Firstly, women selling in a highly dynamic environment may require a combination of sales approaches rather than one single approach. Secondly, using prescriptive criteria (i.e., standard psychological types measured by pencil-andpaper tests) in a normative manner, and matching those profiles to sales conditions, may be a flawed methodology for recruitment and selection decision making. The low predictive validity of Intelligence, Achievement and Personality tests suggests that the latter is a distinct possibility.

The mental mapping procedures outlined here demonstrated a number of predictive indices which analytically discriminates between the more and less successful saleswomen: cognitive complexity is one such indices. Complexity, can be measured as frame complexity using the RepGrid approach or as the more explicit and simply measured and represented form of hierarchy. The data also suggests that the more successfúl saleswomen operating in a highly dynamic market environment produce a much richer and more cognitively complex cognitive structure than the less successful in that environment.

In response to the claim that experts have a more differentiated frame of reference than novices, the results presented here suggest that people with similar levels of experience (but with differing sales performance achievements) produce dissimilar differentiation in their cognitive frames, and which are also qualitatively dissimilar in composition. The cognitive constructs of the more successful saleswoman described above focus on performance characteristics of a business and financial achievement nature, whereas the cognitive constructs of the less successful saleswoman focus on socially oriented performance characteristics.

A plausible explanation of why a more complex mental model correlates with sales success, may be that the cognitively more complex actually search for, or generate, added information about their job. There is considerable evidence to suggest that the cognitive component of decision making centres on a decision maker's cognitive structure of the problem area, and that the available information may influence this structure $[37 ; 38 ; 39 ; 40 ; 41]$. Possibly in dynamic market environments, saleswoman search or additional information of a supportive or nonsupportive type to reduce the uncertainty gap in the cognitive mental set, which in turn leads to a higher level and greater rate of learning about the success factors in the job. The cognitively complex saleswoman may, therefore, leam more effectively and more quickly from their successes and mistakes than the less successful. The cognitively complex are also more open in their thinking and thus more open to, and comfortable with, the dynamics of a changing market environment.

This is a potentially fruitful area of research that would benefit from a longitudinal study.

The two-stage RepGrid/AHP methodology described here offers a considerable advantage over the single RepGrid construct elicitation and mapping process.

The RepGrid alone is a powerful tool for the elicitation of cognitive constructs with which to explore frame differentiation, frame complexity and frame integration, but is an inadequatc tool for investigating construct centrality and the hierarchical structure of the constructs. The construct centrality analysis method proposed by Dunn, et al. [17], (i.e., the arbitrary assignment of weights to each construct to develop a hierarchy of priorities) has significant potential for introducing conceptual inconsistencies into the mental mapping process. AHP is based on a sound and well 
researched theoretical foundation, therefore, it offers a solid base on which to construct decision priorities. The integrated RepGrid/ AHP method addresses the concerns expressed by Kelly [13], in that a hierarchy of priorities for either the one-way or two-way construct relationships can be created.

The RepGridAHP approach also provides a systematic and conceptually consistent methodology for exploring complexity in the form of construct hierarchies. The relationship between selected hierarchical clusters and nodes and, their relationships on a local or global level are additional benefits gained from this two-stage method.

Whilst this study is restricted to a small sample, it does illustrate the value of a potentially productive two-stage process for eliciting and modelling $\mathrm{CSF}^{\text {s }}$. This research also indicates that small enterprises may potentially achieve a competitive advantage in the market place by recruiting, training and deploying salespeople who display a more differentiated and complex mental set than those with a constrained cognitive structure.

A potentiaily powerful system would be the seamless integration of a computer-based RepGrid criteria elicitation system that feeds the data directly into EXPERT CHOICE for prioritising at a local and global level. Such an interactive system would allow for the exploration of frame complexity and consistency in mental models of problem areas over time.

\section{References}

[1] Rickards, T. (1974). Problem-solving Through Greative Analysis. London: Gower Press.

[2] Eden, C., Ackerman, F., \& Cropper, S. (1992). The Analysis of Cause Maps. Jounal of Management Studies, 29(3), Pp.309-324.

[3] Hinkle, D. (1965). The Change of Personal Constructs from the Viewpoint of a Theory of Implications. Unpublished Doctoral Dissertation, Ohio State University.

[4] Simon, H.A. (1981). The Sciences of the Artificial, (2nd Ed), Cambridge, Mass.: MIT Press. Cited in Eden, C, Ackerman, F., \& Cropper, S. (1992). The Analysis of Cause Maps. Joumal of Management Studies, 29(3), Pp.309324.

[S] Saaty, T.L (1980). The Analytic Hierarchy Process. New York:
McGraw-Hill International

[6] Turban, E (1988). Decision Support and Expert Systems: Managerial Perspectives. New York: MacMillan.

[7] Dyer, R.F., \& Forman, E.H. (1991). An analytic approach to marketing decisions. New Jersey: Prentice-Hail.

[8] Saaty, T.L., \& Keams, K.P. (1985) Analytical Planning: The Organization of Systems. RWS Publications, Pittsburgh.

[9] Helmer, O. (1969). Analysis of the Future: The Delphi Method, Santa Monica:Rand Corporation.

[10] Mitroff, I, \& Sagasti, F. (1973). Epistemology as General Systems Theory. Philasophy of the Social Sciencer 3, Pp.117-134.

[11] Hammond, K., \& Alderman, L. (1978). Science, Values and Human Judgement. In Judgement and Decision in Public Policy Formation, Hammond, K. (Ed.) Boulder: Westview.

[12] Raiffa, H. (1969). Preferences for Multiattribute Alternatives. Memorandum RM-5968-DOT/RC Santa Monica: Rand Corporation.

[13] Kelly, G.A. (1955). The Psychology of Personal Constructs, New York, Norton, Vols 1 \& 2.

[14] Brook, J.A., \& Brook R.J. (1989). Exploring the Meaning of Work and Nonwork, Joumal of Otganizational Behavior, 10, Pp.169-178.

[15] Smith. M. (1980). An Analysis of Three Managerial Jobs Using Repertory Grids. Journal of Management Studies, May, Pp.205213.

[16] Dunn, W.N., \& A. Ginsberg, A. (1986). A Sociocognitive Network Approach to Organizational Analysis, Human Relations, 40, Pp.955-976.

[1]] Dunn, W.N., Pavlak, T.J., \& Roberts G.E. (1987). Cognitive Performance Appraisal 'Mapping Managers' Category Struchires Using the Grid Technique, Personnel Review, 16 (3), Pp.16-19.

[18] Senge, P.M. (1990). The Fifth Discipline. New York: Doubleday.

[19] Stewart, V., \& Stewart. A. (1981). Business Applications of Repertory Grid, McGraw Hill, London.

[20] Landfield, A.W. \& Schmindiel, C.J. (1983) The Interpersonal Transaction Group: Evolving Measurements in the Pursuit of Theory. in J. Mancuso, \& J. 
Adams-Webber. (Eds) Applications of Personal Construct Theory, Toronto: Acardemic Press.

[21] Landfield, A.W. (1971). Personal Construct Systems in Psychotherapy. Chicago: Rand McNally.

[22] Fransella, F., \& Bannister, D. (1977). A Manual for Repertory Grid Technique. New York: Academic Press.

[23] Landfield, A.W. (1982), A Construction of Fragmentation and Unity. In J. Mancuso, , \& J. AdamsWebber. (Eds), Systems of Personal Constructs. New York: Praeger.

[24] Stevens, H.P. (1989). Matching Sales Skills to Customer Needs, Management Review, 78, No.6, Pp.45-47.

[25] Argyris, C. (1954). Organization of a Bank. New Haven: Yale Labor and Management Centre.

[26] Argyris, C (1957), Personality and Organization. New York: Harper.

[27] Schein, E.H. (1968). Organizational Socialization and the Profession of Management Industrial Management Review, 9, Pp.1-16.

[28] Morse, J.J. (1975). Person-job Congruence and Individual Adjustment. Human Relations, 28, Pp.841-861.

[29] Schneider, B. (1975a). Organizational Climate: An Essay. Personnel Asychology, 28, Pp.448-481.

[30] Schneider, B. (1975b). Organisational Climate:Individual Preferences and Organizational Realities Revisited. Journal of Applied Asychology, 60 , Pp.459-46.5.

[31] Wanous, J.P. (1980). Organizational Entry: Recruitment, Selection, and Socialization of Newcomers. AddisonWesley, Reading Mass.
[32] Greenberg, H.M., \& Greenberg, J. (1980). Job Matching for Better Salcs Performance, Harvard Business Review, September-October, Pp.128133.

[33] Cattell, R.B. \& Eber, H.W. (1964). Handbook for the Sixteen Personality Factor Questionnaire. Champaign, Ill.: Institute for Personality and Ability Testing.

[34] Bell, R.C (1987). G-PACK: Repertory Grid Programme Package (Version 3), Psychstat, Melbourne.

[35] Saaty, T.L, \& Vargas, LG. (1991). The Logic of Priorities. Pittsburgh: RWS Publications.

[36] Expert Choice (Version 8) Sourced from Expert Choice Inc. Pittsburgh, Pennsylvania U.S.A.

[37] Schrocder, H.M., Diver, M.J., \& Streufert, S. (1967). Human information Processing, New York: Holt, Rinehart \& Einston.

[38] Nyström, H. (1979). Creativity and Innovation, New York: Wiley.

[39] Schwenk, C.R. (1984). Cognitive Simplification Processes in Strategic Decision-making.Strategic Management Joumal, 5, Pp.111-128.

[40] Schwenk, CR. (1988). The Cognitive Perspective on Strategic Decision Making, Joumal of Management Studies, 25, (1), Pp.41-55.

[41] Fahey, L., \& Narayanan. V.K. (1989). Linking Changes in Revealed Causal Maps and Environmental Change: An Empirical Study, Journal of Management Studies, 26, (4), Pp.361378. 